\title{
ОПТИМИЗАЦИЯ МОДЕЛИ ОКАЗАНИЯ ГОСУДАРСТВЕННЫХ УСЛУГ В СФЕРЕ КАДАСТРОВОГО УЧЕТА НА ОСНОВЕ АВТОМАТИЗАЦИИ ПРОЦЕССА КАДАСТРОВОЙ УЧЕТНО-РЕГИСТРАЦИОННОЙ ДЕЯТЕЛЬНОСТИ
}

\author{
(C) 2021 Воронова Ольга Владимировна \\ кандидат экономических наук, доцент \\ Санкт-Петербургский политехнический университет Петра Великого, Россия, Санкт-Петербург \\ (c) 2021 Хныкина Татьяна Семеновна \\ кандидат экономических наук, доцент \\ Санкт-Петербургский политехнический университет Петра Великого, Россия, Санкт-Петербург

\section{(c) 2021 Ильина Ирина Витальевна} \\ ассистент \\ Санкт-Петербургский политехнический университет Петра Великого, Россия, Санкт-Петербург
}

\section{(c) 2021 Садакова Виктория Владимировна \\ ведущий специалист ФГБУ «ФКП Росреестр»}

В статье предложена модель оптимизации оказания государственных услуг в сфере кадастрового учета на основе автоматизации процесса кадастровой учетно-регистрационной деятельности. В процессе исследования проведена оценка качества оказания государственных услуг в сфере кадастрового учета. Для этого был осуществлен анализ основных, управляющих и поддерживающих бизнес-процессов и установлены их ключевые показатели эффективности. В процессе исследования выявлены такие проблемные аспекты деятельности как скорость и качество услуг, предоставляемых предприятиями кадастрового учета, коммуникация и удобство предлагаемых сервисов для потенциальных заявителей, а также отсутствие единого ресурса, объединяющего пространственные данные всех ведомств, обладающих полномочиями в сфере регистрации недвижимого имущества.

В результате проведенного анализа были выявлены такие потенциально перспективные бизнеспроцессы для реинжиниринга как «Упрощение интерфейса взаимодействия заявителей с Кировской кадастровой палатой» и «Автоматизация процесса кадастровой учетно-регистрационной деятельности». По выявленным процессам разработаны целевые модели, ключевые показатели эффективности, а также дорожные карты, отображающие пошаговый сценарий развития организации в заданном направлении до 01.01.2023 года.

Ключевые слова: бизнес процессы, бизнес-модель, реинжиниринг, целевая модель.

\section{1. Введение}

Основу для воздействия государства на отношения в обществе, возникающие по поводу недвижимости, создают в совокупности кадастровый учет, оценка, регистрация прав и налогообложение на недвижимое имущество. Государственные услуги в сфере недвижимости в Кировской области в наибольшей степени предоставляются территориальными органами министерств и ведомств и МФЦ, около 700 специалистов обеспечивают их оказание [1,2]. Однако и здесь пандемия COVID-19 оказала существенное влияние: если в начале 2020 г. доля электронных услуг составляла приблизительно $20 \%$, то к началу 2021 г. она выросла в полтора раза; увеличилось число запросов на выездной приём документов; появилась острая необходимость усовершенствовать современные сервисы и технологии. Наиболее приоритетными являются две стратегические области развития: цифровизация и повышение качества предоставляемых услуг [3].

При анализе деятельности Филиала был использован процессный подход, то есть концепция управления, при которой все управление деятельностью предприятия в целом рассматривается как набор бизнес-процессов, которыми необходимо управлять для улучшения качества работы организации. Следовательно, оценка качества государственных услуг в кадастровой палате представляет собой высоко актуальный предмет для исследования.

В рамках настоящей работы, в продолжение исследования, посвященного разработке референтной бизнес модели предприятия кадастро- 
вого учета, рассмотрим основные проблемы, возникающие в организациях рассматриваемого типа.

\section{2. Результаты}

Проанализировав отзывы и комментарии пользователей о работе Кировской кадастровой палаты, результаты опроса директора филиала и сотрудников отдела подготовки сведений и межрайонного отдела, которые непосредственно вовлечены в процесс оказания государственных услуг, а также результаты интервью с гражданами, обращавшимися в Федеральную кадастровую палату Росреестра были выявлены проблемные места для заявителей. Для удобства проблемы были объединены в 4 категорий [4,5].

При этом необходимо отметить, что посредством системы обратной связи «Ваш контроль», в которой заявители оценивают вежливость и профессионализм регистраторов, скорость их работы, удобство процедуры, уровень комфорта в помещениях и т.д. качество услуг Росреестра по итогам первого полугодия 2020 было высоко оценено [6]. Средняя оценка работы ведомства - 4,92 по пятибалльной шкале, при этом в 2019 году эта оценка составляла 4,89 балла по
Кировской области, то есть граждане стали чаще положительно оценивать услуги Росреестра [7].

Рассмотрим проект плана мероприятий по повышению качества предоставления государственных услуг для Кировской кадастровой палаты. Предложения по повышению качества предоставления государственных услуг для Кировской кадастровой палаты будут представлены в виде наиболее часто применяемого в ведомстве инструмента планирования - дорожных карт. Дорожная карта («Roadmapping») - наглядное отображение задач, прогресса и пошагового сценария развития организации в заданном направлении в длительной перспективе [8]. В нее входят цели, этапы, сроки достижения задач и основные целевые показатели. Дорожная карта обеспечивает информационную поддержку процессу принятия управленческих решений, способствует формированию у сотрудников представления о взаимосвязях между процессами на любом промежутке времени [9].

Дорожные карты будут разработаны по двум целевым моделям устранения «болевых точек» заявителей с целью повышения качества предоставления государственных услуг [10].

Таблица 1. Список выявленных проблемных мест в оказании услуг Кировской кадастровой палатой

\begin{tabular}{|c|c|}
\hline Категория & Проблемные места \\
\hline \multirow{3}{*}{ Низкая скорость } & Нарушение срока оказания услуги \\
\hline & Медленный документооборот между МФЦ и ФГБУ «ФКП Росреестра» \\
\hline & Медленное поступление госпошлин \\
\hline \multirow{5}{*}{ Не настроены коммуникации } & Нет оповещений о статусе, приостановках и готовности \\
\hline & Нельзя онлайн узнать причину приостановки \\
\hline & Сайты двойники Росреестра, ненадежные посредники \\
\hline & Сложно дозвониться до контактного центра \\
\hline & $\begin{array}{l}\text { Отсутствует единый ресурс, объединяющий пространственные данные всех } \\
\text { ведомств, обладающих полномочиями в сфере регистрации недвижимого } \\
\text { имущества }\end{array}$ \\
\hline \multirow{5}{*}{ Низкое качество услуг } & Технические ошибки на сайте, в ЛК \\
\hline & $\begin{array}{l}\text { Технические ошибки МФЦ при подаче (не те документы, неполный пакет } \\
\text { документов и т.д.) }\end{array}$ \\
\hline & Технической ошибки при рассмотрении заявки \\
\hline & Технические ошибки при выгрузке данных \\
\hline & $\begin{array}{l}\text { Некоторые документы обрабатываются вручную из-за неполноты данных в } \\
\text { ЕГРН }\end{array}$ \\
\hline \multirow{5}{*}{$\begin{array}{l}\text { Сложно и неудобно для } \\
\text { заявителей }\end{array}$} & Нет онлайн записи в ФГБУ «ФКП Росреестра» \\
\hline & $\begin{array}{l}\text { Недостаточно разъяснений по пакету документов, бюрократичное непонят- } \\
\text { ное описание причин приостановки }\end{array}$ \\
\hline & $\begin{array}{l}\text { Трудности в оформлении сделок с гражданами и организациями в элек- } \\
\text { тронном виде }\end{array}$ \\
\hline & Сложный процесс предоставления услуги с эл. подписью \\
\hline & $\begin{array}{l}\text { Отсутствие автоматической выдачи выписок при типовых ситуациях, тре- } \\
\text { бующих выписки ЕГРН }\end{array}$ \\
\hline
\end{tabular}




\section{3. Обсуждение}

Целевая модель «Упрощение интерфейса взаимодействия заявителей с Кировской кадастровой палатой» направлена на повышение эффективности работы каналов прямой связи заявителей и филиала. Основные цели модели: создание благоприятных условий для взаимодействия, увеличение степени удовлетворенности граждан государственными услугами, стимулирование спроса на услуги. Модель, реализуя весь практический опыт взаимодействия заявителей с Кировской кадастровой палатой, является набором минимально необходимых действий по следующим направлениям:

- проектирование клиентского опыта;

- формирование механизмов обратной связи;

- повышение уровня информированности заявителей и т.д [11].

Реализация целевой модели в Кировской области будет осуществляться в три этапа до начала 2023 года. Исполнительные органы государственной власти Кировской области вправе руководствоваться предлагаемыми последовательными переходными значениями целевых показателей или установить иные [12,13]. Ниже представлена целевая модель «Упрощение интерфейса взаимодействия заявителей с Киров- ской кадастровой палатой», разложенная по факторам: уровень информированности заявителей, проектирование клиентского опыта, доступность подачи заявления.

Целевая модель «Автоматизация процесса кадастровой учетно-регистрационной деятельности» позволяет сократить сроки прохождения процедур кадастровой учетно-регистрационной деятельности, систематизировать и усилить контроль над процессом предоставления услуг в целом [14]. Ниже представлена целевая модель «Автоматизация процесса кадастровой учетнорегистрационной деятельности».

Качество и эффективность организации процессов автоматизации формируют четкие правила организации контроля и защиты прав заявителей, снижают административную нагрузку на сотрудников ФКП и МФЦ, стимулируют заявителей не использовать ненадежных посредников и сайтов-двойников Росреестра [15].

Реализация целевой модели в Кировской области будет осуществляться в три этапа до начала 2023 года. Исполнительные органы государственной власти Кировской области вправе руководствоваться предлагаемыми последовательными переходными значениями целевых показателей или установить иные [16,17].

Таблица 2. Целевая модель «Упрощение интерфейса взаимодействия заявителей с Кировской кадастровой палатой». Фактор «уровень информированности заявителей»

\begin{tabular}{|c|c|c|c|c|}
\hline \multirow[b]{2}{*}{$\begin{array}{c}\text { Необходимые меры для } \\
\text { повышения эффективности }\end{array}$} & \multirow[b]{2}{*}{$\begin{array}{c}\text { Показатели, характеризующие степень } \\
\text { достижения результата }\end{array}$} & \multicolumn{3}{|c|}{$\begin{array}{l}\text { Целевое значение } \\
\text { показателей }\end{array}$} \\
\hline & & 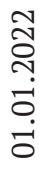 & 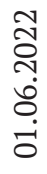 & 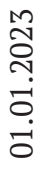 \\
\hline $\begin{array}{l}\text { Разработка на основе анализа информа- } \\
\text { ции из личного кабинета возможности } \\
\text { информирования заявителя о доступных } \\
\text { ему услугах в электронном виде }\end{array}$ & $\begin{array}{l}\text { Наличие информирования заявителя о } \\
\text { доступных ему услугах в электронном } \\
\text { виде, да/нет }\end{array}$ & 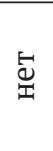 & 芘 & $\underset{\pi}{\pi}$ \\
\hline \multirow{2}{*}{$\begin{array}{l}\text { Информирование потенциальных } \\
\text { заявителей о преимуществах использо- } \\
\text { вания электронных услуг по кадастровой } \\
\text { учетно-регистрационной деятельности }\end{array}$} & $\begin{array}{l}\text { Доля граждан, использующих элек- } \\
\text { тронные онлайн услуги по кадастровой } \\
\text { учетно-регистрационной деятельности, } \\
\text { не менее \% }\end{array}$ & $\begin{array}{l}0 \\
\text { की }\end{array}$ & $\stackrel{0}{0}$ & $\stackrel{\circ}{\infty}$ \\
\hline & $\begin{array}{l}\text { Доля юридических лиц, электронные } \\
\text { онлайн услуги по кадастровой учетно- } \\
\text { регистрационной деятельности, не } \\
\text { менее \% }\end{array}$ & on & ?. & $\stackrel{0}{\circ}$ \\
\hline $\begin{array}{l}\text { Размещение информации о возможно- } \\
\text { сти получения государственных услуг } \\
\text { Кировской кадастровой палаты в элек- } \\
\text { тронном виде в СМИ }\end{array}$ & $\begin{array}{l}\text { Количество пресс-релизов, не менее еди- } \\
\text { ниц в квартал }\end{array}$ & $\begin{array}{c}0 \\
M\end{array}$ & $\stackrel{0}{f i}$ & $\stackrel{0}{\circ}$ \\
\hline
\end{tabular}


Таблица 3. Целевая модель «Упрощение интерфейса взаимодействия заявителей с Кировской кадастровой палатой». Фактор «проектирование клиентского опыта»

\begin{tabular}{|c|c|c|c|c|c|}
\hline \multirow[b]{2}{*}{$\begin{array}{l}\stackrel{0}{0} \\
\text { 章 } \\
\text { Өે }\end{array}$} & \multirow[b]{2}{*}{$\begin{array}{c}\text { Необходимые меры для повышения } \\
\text { эф-ти }\end{array}$} & \multirow[b]{2}{*}{$\begin{array}{l}\text { Показатели, характеризующие } \\
\text { степень достижения результата }\end{array}$} & \multicolumn{3}{|c|}{$\begin{array}{l}\text { Целевое значение } \\
\text { показателей }\end{array}$} \\
\hline & & & స̃ & 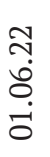 & 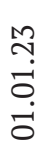 \\
\hline \multirow{4}{*}{ 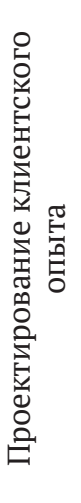 } & $\begin{array}{l}\text { Системный анализ целевых аудито- } \\
\text { рий пользователей электронных услуг } \\
\text { Кировской кадастровой палаты }\end{array}$ & $\begin{array}{l}\text { Портреты целевых аудиторий пользо- } \\
\text { вателей электронных услуг Кировской } \\
\text { кадастровой палаты, да/нет }\end{array}$ & $\tilde{E}$ & $\underset{\sigma}{\pi}$ & $\tilde{\sigma}$ \\
\hline & \multirow{3}{*}{$\begin{array}{l}\text { Разработка на официальном портале } \\
\text { Росреестра интерфейсов жизненных } \\
\text { ситуаций с привлечением дизайнеров } \\
\text { UX (опыта пользователей) }\end{array}$} & $\begin{array}{l}\text { Наличие на официальном сайте ин- } \\
\text { терфейсов жизненных ситуаций, да/ } \\
\text { нет }\end{array}$ & $\stackrel{\underline{4}}{\underline{T}}$ & $\underset{\sigma}{\pi}$ & $\widetilde{\sigma}$ \\
\hline & & $\begin{array}{l}\text { Продолжительность активности при } \\
\text { одном сеансе, минут }\end{array}$ & 은 & $\stackrel{\circ}{\circ}$ & $\begin{array}{l}0 \\
\stackrel{2}{n}\end{array}$ \\
\hline & & $\begin{array}{l}\text { Доля услуг по учетно- } \\
\text { регистрационным действиям в элек- } \\
\text { тронном виде, в общем количестве } \\
\text { таких услуг, \% }\end{array}$ & $\stackrel{0}{\circ}$ & $\stackrel{0}{\infty}$ & ஜे \\
\hline
\end{tabular}

Таблица 4. Целевая модель «Упрощение интерфейса взаимодействия заявителей с Кировской кадастровой палатой». Фактор «доступность подачи заявлений»

\begin{tabular}{|c|c|c|c|c|}
\hline \multirow[b]{2}{*}{$\begin{array}{c}\text { Необходимые меры для повышения } \\
\text { эффективности }\end{array}$} & \multirow[b]{2}{*}{$\begin{array}{c}\text { Показатели, характеризующие степень } \\
\text { достижения результата }\end{array}$} & \multicolumn{3}{|c|}{$\begin{array}{c}\text { Целевое значение } \\
\text { показателей }\end{array}$} \\
\hline & & 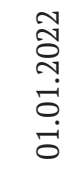 & 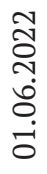 & 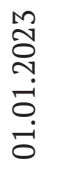 \\
\hline \multirow{2}{*}{$\begin{array}{l}\text { Смена бюрократического языка информа- } \\
\text { ции о порядке и условиях получения услуг } \\
\text { по учетно-регистрационным действия на } \\
\text { более понятный пользователю официаль- } \\
\text { ного портала Федеральной кадастровой } \\
\text { палаты Росреестра }\end{array}$} & $\begin{array}{l}\text { Продолжительность активности при одном } \\
\text { сеансе, минут }\end{array}$ & เ્ & $\stackrel{\text { Oे }}{\stackrel{0}{0}}$ & 음 \\
\hline & $\begin{array}{l}\text { Уровень удовлетворенности заявителей } \\
\text { качеством официального портала, средний } \\
\text { балл оценки (из } 5 \text { возможных) }\end{array}$ & $\stackrel{+}{f i}$ & $\stackrel{0}{f}$ & $\stackrel{\infty}{f^{-}}$ \\
\hline $\begin{array}{l}\text { Перевод на английский язык всех матери- } \\
\text { алов официального портала Федеральной } \\
\text { кадастровой палаты Росреестра }\end{array}$ & $\begin{array}{l}\text { Ссылка на англоязычную версию офици- } \\
\text { ального портала Федеральной кадастровой } \\
\text { палаты Росреестра, да/нет }\end{array}$ & 采 & שٓ & 苔 \\
\hline $\begin{array}{l}\text { Контроль доступности услуг, предоставля- } \\
\text { емых МФЦ по Кировской области, по пока- } \\
\text { зателю нагрузки на } 1 \text { окно (нагрузка на } 1 \\
\text { окно не должна превышать установленного } \\
\text { целевого значения показателя) }\end{array}$ & $\begin{array}{l}\text { Количество заявлений по учетно- } \\
\text { регистрационным действиям на } 1 \text { окно, не } \\
\text { более штук в день }\end{array}$ & $\stackrel{M}{N}$ & ำ & ำ \\
\hline
\end{tabular}


Таблица 5. Целевая модель «Автоматизация процесса кадастровой учетно-регистрационной деятельности». Фактор «уровень развития онлайн-сервисов в сфере учетно-регистрационных действий»

\begin{tabular}{|c|c|c|c|c|}
\hline \multirow[b]{2}{*}{$\begin{array}{c}\text { Необходимые меры для повышения } \\
\text { эффективности }\end{array}$} & \multirow[b]{2}{*}{$\begin{array}{c}\text { Показатели, характеризующие степень } \\
\text { достижения результата }\end{array}$} & \multicolumn{3}{|c|}{$\begin{array}{l}\text { Целевое значение } \\
\text { показателей }\end{array}$} \\
\hline & & 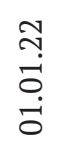 & $\begin{array}{l}\text { Ñ} \\
\dot{0} \\
\dot{0}\end{array}$ & 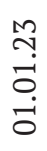 \\
\hline $\begin{array}{l}\text { Применение искусственного интеллекта } \\
\text { в части первичной проверки качества } \\
\text { сканирования входящих документов и их } \\
\text { распознавания }\end{array}$ & $\begin{array}{l}\text { Доля принятых пакетов документов, при } \\
\text { принятии которых сотрудник не осуще- } \\
\text { ствил или некачественно осуществил ска- } \\
\text { нирование, в общем количестве пакетов } \\
\text { документов, \% }\end{array}$ & in & $\stackrel{\circ}{\circ}$ & in \\
\hline $\begin{array}{l}\text { Применение искусственного интеллекта } \\
\text { в части проведения первичной правовой } \\
\text { экспертизы (сопоставление данных из } \\
\text { ЕГРН с данными поданных документов) }\end{array}$ & $\begin{array}{l}\text { Средний фактический срок оказания ус- } \\
\text { луг по учетно-регистрационным действи- } \\
\text { ям по заявлениям, поданным через МФЦ, } \\
\text { рабочих дней }\end{array}$ & $\begin{array}{l}0 \\
\infty\end{array}$ & $\begin{array}{l}0 \\
0\end{array}$ & 요 \\
\hline $\begin{array}{l}\text { Автоматизированное предоставление } \\
\text { отчета об ошибках и информации о } \\
\text { системных проблемах, возникающих при } \\
\text { получении услуг по кадастровой учетно- } \\
\text { регистрационной деятельности филиала } \\
\text { ФГБУ «Федеральной кадастровой палаты } \\
\text { Росреестра» по Кировской области }\end{array}$ & $\begin{array}{l}\text { Средний фактический срок оказания } \\
\text { услуг по учетно-регистрационным дей- } \\
\text { ствиям по заявлениям, поданным через } \\
\text { Кировскую кадастровую палату электрон- } \\
\text { но, рабочих дней }\end{array}$ & $\underset{N}{\circ}$ & in & ì \\
\hline
\end{tabular}

Таблица 6. Целевая модель «Автоматизация процесса кадастровой учетно-регистрационной деятельности». Фактор «межведомственное взаимодействие посредством электронной системы»

\begin{tabular}{|c|c|c|c|c|}
\hline \multirow[b]{2}{*}{ Необходимые меры для повышения эф-ти } & \multirow[b]{2}{*}{$\begin{array}{c}\text { Показатели, характеризующие степень до- } \\
\text { стижения результата }\end{array}$} & \multicolumn{3}{|c|}{$\begin{array}{l}\text { Целевое значе- } \\
\text { ние показате- } \\
\text { лей }\end{array}$} \\
\hline & & $\frac{\text { ஸ̃ }}{\dot{\sigma}}$ & $\begin{array}{l}\text { ָै } \\
\stackrel{0}{0} \\
\dot{0}\end{array}$ & 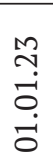 \\
\hline \multirow{2}{*}{$\begin{array}{l}\text { Разработка и внедрение информационной } \\
\text { системы для предоставления органами вла- } \\
\text { сти Кировской области и органами местного } \\
\text { самоуправления сведений необходимых } \\
\text { в предоставлении государственных услуг, } \\
\text { исключительно в электронном виде, позво- } \\
\text { ляющей перейти к межведомственному и } \\
\text { межуровневому взаимодействию }\end{array}$} & $\begin{array}{l}\text { Доля ответов на запросы Кировской када- } \\
\text { стровой палаты, полученных в электронном } \\
\text { виде, в общем количестве запросов,\% }\end{array}$ & $\begin{array}{l}0 \\
\text { in }\end{array}$ & $\begin{array}{l}0 \\
\text { in }\end{array}$ & $\begin{array}{l}\circ \\
\infty\end{array}$ \\
\hline & $\begin{array}{l}\text { Количество направлений деятельности, по } \\
\text { которым осуществляется электронное меж- } \\
\text { ведомственное взаимодействие, не менее } \\
\text { штук }\end{array}$ & $\begin{array}{c}0 \\
m\end{array}$ & $\begin{array}{l}0 \\
\text { in }\end{array}$ & $\stackrel{\circ}{\circ}$ \\
\hline \multirow{2}{*}{$\begin{array}{l}\text { Заключение соглашений о подключении } \\
\text { к веб-сервисам Росреестра (ФГИС ЕГРН) } \\
\text { застройщиков Кировской области }\end{array}$} & $\begin{array}{l}\text { Количество соглашений о подключении к } \\
\text { ФГИС ЕГРН застройщиков Кировской обла- } \\
\text { сти, не менее штук }\end{array}$ & in & $\begin{array}{l}0 \\
\equiv\end{array}$ & 옹 \\
\hline & $\begin{array}{l}\text { Доля застройщиков Кировской области, под- } \\
\text { ключенная к ФГИС ЕГРН, не менее\% }\end{array}$ & $\begin{array}{l}0 \\
\text { in } \\
\rightarrow\end{array}$ & $\stackrel{0}{0}$ & $\stackrel{\circ}{\circ}$ \\
\hline $\begin{array}{l}\text { Разработка сервиса «калькулятор процедур» } \\
\text { (онлайн-инструмент для застройщиков, } \\
\text { демонстрирующий для конкретного строи- } \\
\text { тельного проекта сроки и этапы прохожде- } \\
\text { ния процедур) }\end{array}$ & $\begin{array}{l}\text { Наличие онлайн-сервиса «калькулятора } \\
\text { процедур», да/нет }\end{array}$ & 矛 & 它 & $\underset{\sigma}{\pi}$ \\
\hline
\end{tabular}


Таблица 7. Целевая модель «Автоматизация процесса кадастровой учетно-регистрационной деятельности». Фактор «продвижение официального портала Федеральной кадастровой палаты Росреестра»

\begin{tabular}{|c|c|c|c|c|}
\hline \multirow[b]{2}{*}{ Необходимые меры для повышения эф-ти } & \multirow[b]{2}{*}{$\begin{array}{c}\text { Показатели, характеризующие степень } \\
\text { достижения результата }\end{array}$} & \multicolumn{3}{|c|}{$\begin{array}{c}\text { Целевое значение } \\
\text { показателей }\end{array}$} \\
\hline & & 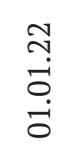 & 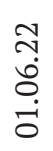 & 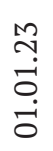 \\
\hline $\begin{array}{l}\text { Развитие продвижения официального } \\
\text { портала Федеральной кадастровой палаты } \\
\text { Росреестра }\end{array}$ & $\begin{array}{l}\text { Место выдачи в 2-х крупнейших поиско- } \\
\text { вых системах (Google и Yandex) по соот- } \\
\text { ветствующим запросам, место }\end{array}$ & $\stackrel{\circ}{\mathrm{i}}$ & $\stackrel{\circ}{\rightarrow}$ & $\stackrel{0}{-}$ \\
\hline $\begin{array}{l}\text { Учет динамики количества посетителей } \\
\text { официального портала Государственных } \\
\text { услуг Кировской области }\end{array}$ & $\begin{array}{l}\text { Количество посещений, не менее единиц } \\
\text { в день }\end{array}$ & $\begin{array}{l}O \\
\text { in } \\
M\end{array}$ & $\begin{array}{l}0 \\
8 \\
0\end{array}$ & $\begin{array}{l}0 \\
\text { ஸी }\end{array}$ \\
\hline $\begin{array}{l}\text { Развитие социальных сетей при продви- } \\
\text { жении официального портала Федераль- } \\
\text { ной кадастровой палаты Росреестра }\end{array}$ & $\begin{array}{l}\text { Ссылки на официальный портал Феде- } \\
\text { ральной кадастровой палаты Росреестра в } \\
\text { социальных сетях, да/нет }\end{array}$ & 茞 & $\tilde{E}$ & $\pi$ \\
\hline $\begin{array}{l}\text { Внедрение системы «Антифрод» (поиск } \\
\text { сайтов-двойников; системы предотвра- } \\
\text { щения утечек данных базы ЕГРН; средства } \\
\text { аутентификации и защиты от несанкцио- } \\
\text { нированного доступа и др.) }\end{array}$ & $\begin{array}{l}\text { Доля заявлений по учетно- } \\
\text { регистрационным действиям, поданных } \\
\text { в электронном виде, в общем количестве } \\
\text { таких заявлений,\% }\end{array}$ & $\begin{array}{l}\circ \\
\text { if } \\
\text { f }\end{array}$ & $\begin{array}{l}0 \\
\text { in }\end{array}$ & $\begin{array}{l}0 \\
\text { in } \\
\infty\end{array}$ \\
\hline
\end{tabular}

\section{4. Заключение}

Для того чтобы проводить реинженеринг бизнес-процессов с упором на клиентоориентированный путь, были выявлены основные проблемные места для заявителей государственных, которые были объединены в 4 категорий:

- низкая скорость;

- не настроены коммуникации;

- низкое качество услуг;

- сложно и неудобно для заявителей.

Предложения по повышению качества услуг для Кировской палаты представлены в виде дорожных карт - инструмента для наглядного отображение задач, прогресса и пошагового сценария развития организации в заданном направлении в длительной перспективе. Дорожные карты разработаны по 2 целевым моделям устранения «болевых точек» заявителей, а именно: целевая модель «Упрощение интерфейса взаимодействия заявителей с Кировской кадастровой палатой», направленная на повышение эффективности работы каналов прямой связи заявителей и филиала, и целевая модель «Автоматизация процесса кадастровой учетнорегистрационной деятельности», позволяющая сократить сроки прохождения процедур кадастровой учетно-регистрационной деятельности, систематизировать и усилить контроль над процессом предоставления услуг в целом.

Таким образом, разработанные с целью повышения качества предоставления государственных услуг по учетно-регистрационным действиям дорожные карты по двум целевым моделям устранения «болевых точек» заявителей обеспечат информационную поддержку процессу принятия управленческих решений и будут способствовать формированию у сотрудников представления о взаимосвязях между процессами на любом промежутке времени.

\section{Библиографический список}

1. Официальный сайт правительства Кировской области [Электронный ресурс].- Режим доступа: https:/ kirovreg.ru/ (дата обращения: 07.04.2021).

2. Официальный сайт ЦИАН [Электронный ресурс].- Режим доступа: https:/kirov.cian.ru/ (дата обращения: 13.04.2021).

3. Ilin I., Voronova O., Knykina T. Improvement of the business model of network retail in fmcg sector. В сборнике: Proceedings of the 33rd International Business Information Management Association Conference, IBIMA 2019: Education Excellence and Innovation Management through Vision 2020. 33, Education Excellence and Innovation Management through Vision 2020. 2019. C. 5112-5121. 
4. Бусов, В.И. Управление недвижимостью: теория и практика [: учебник для академического бакалавриата / В.И. Бусов, А.А. Поляков.- М.: Издательство Юрайт, 2019.- 517 с.

5. Официальный портал государственных услуг Кировской области [Электронный ресурс].- Режим доступа: http://www.gosuslugi43.ru/web/guest/main (дата обращения: 14.05.2021).

6. Официальный портал ежедневного онлайн-издания D-russia.ru (от Digital Russia) [Электронный ресурс].Режим доступа: https://d-russia.ru/ (дата обращения: 14.05.2021).

7. Акифьев И.В., Чеботарева И.П., Бордукова О.М. Цифровизация деятельности кадастровой палаты: состояние, проблемы и перспективы. Образование и наука в современном мире. Инновации. 2021. № 3 (34). С. $140-144$.

8. Александров, Д. В. Моделирование и анализ бизнес-процессов [Текст]: учебник / Д. В.Александров.- Саратов: Ай Пи Эр Медиа, 2018.-233 с.

9. ISO 9001:2015 «Quality management systems - Requirements» - IDT, 2015. - P. 10-11.

10. Воронова О.В., Ильин И.В., Харева В.А. Разработка архитектурной модели бизнес-сервисов системы взаимодействия с потребителями сетевых торговых компаний. Известия Санкт-Петербургского государственного экономического университета. 2020. № 6 (126). С. 86-92.

11. Евграфов А.А., Ильина О.В. Сервисный менеджмент: концептуальное видение и механизм реализации. Международный научный журнал. 2017. № 1. С. 7-15.

12. Самохвалова С.Г., Новоселова Е.Ф. Информационная система удаленного мониторинга компьютеров фбу «земельная кадастровая палата. Вестник Амурского государственного университета. Серия: Естественные и экономические науки. 2012. № 59. С. 55-59.

13. Елиферов, В.Г. Бизнес-процессы: Регламентация и управление: учебник / В.Г.Елиферов.- М.: НИЦ ИНФРА-М, 2019.- 319 с.

14. Официальный сайт «Business process management initiative»[Электронный ресурс].- Режим доступа: https://www.bpmn.org/ (дата обращения: 16.05.2021).

15. Репин, В.В. Бизнес-процессы. Моделирование, внедрение, управление / В. В.Репин.- М.: Манн, Иванов и Фербер, 2019.- 512 c.

16. Воронова, О.В. Референтная модель бизнес-процессов верхнего уровня для построения архитектурных решений сетевых компаний FMCG-ритейла / О. В. Воронова, И. В. Ильин // Экономика и управление. - 2019.№ 5(163). - С. 81-88.

17. Левина, А.И. Функционально-ориентированное проектирование информационных систем инфраструктурноемких предприятий / А.И.Левина, А.Д.Борреманс, А.А.Лепехин // Перспективы науки. - 2018.№ 11(110).- С. 35-39. 